\title{
Natural products, an important resource for discovery of multitarget drugs and functional food for regulation of hepatic glucose metabolism
}

This article was published in the following Dove Press journal:

Drug Design, Development and Therapy

\author{
Jian $\mathrm{Li}^{1, *}$ \\ Haiyang $\mathrm{Yu}^{2, *}$ \\ Sijian Wang' \\ Wei Wang ${ }^{3}$ \\ Qian Chen' \\ Yanmin $\mathrm{Ma}^{2}$ \\ Yi Zhang' \\ Tao Wang'
}

'Tianjin State Key Laboratory of Modern Chinese Medicine, Tianjin, ${ }^{2}$ Department of Phytochemistry, Institute of Traditional Chinese Medicine, Tianjin University of Traditional Chinese Medicine, Tianjin, China; ${ }^{3}$ Internal Medicine, Houston Methodist Hospital, Houston, TX, USA

*These authors contributed equally to this work
Correspondence: Yi Zhang; Tao Wang Tianjin State Key Laboratory of Modern Chinese Medicine, 312 Anshanxi Road, Nankai District, Tianjin 300193, China

Tel/fax +862259596163

Email zhwwxzh@263.net;

wangtao@tjutcm.edu.cn

\begin{abstract}
Imbalanced hepatic glucose homeostasis is one of the critical pathologic events in the development of metabolic syndromes (MSs). Therefore, regulation of imbalanced hepatic glucose homeostasis is important in drug development for MS treatment. In this review, we discuss the major targets that regulate hepatic glucose homeostasis in human physiologic and pathophysiologic processes, involving hepatic glucose uptake, glycolysis and glycogen synthesis, and summarize their changes in MSs. Recent literature suggests the necessity of multitarget drugs in the management of MS disorder for regulation of imbalanced glucose homeostasis in both experimental models and MS patients. Here, we highlight the potential bioactive compounds from natural products with medicinal or health care values, and focus on polypharmacologic and multitarget natural products with effects on various signaling pathways in hepatic glucose metabolism. This review shows the advantage and feasibility of discovering multicompound-multitarget drugs from natural products, and providing a new perspective of ways on drug and functional food development for MSs.
\end{abstract}

Keywords: hepatic glucose metabolism, natural products, multitarget, metabolic syndromes, drug and functional food development integrative medicine

\section{Introduction}

Glucose homeostasis is an essential metabolic process of mammalian organisms based upon a series of biochemical reactions. Glucose homeostasis can be divided into three phases: glucose absorption and organ distribution, glycolysis and glycogen synthesis, glycogenolysis and gluconeogenesis.

The liver is an organ that performs essential functions for glucose homeostasis. Portal vein is the functional vascular system of the liver. Seventy to eighty percent of the blood supply comes from the portal vein, which is enriched with nutrients, such as sugars, amino acids, vitamins, essential fatty acids and so on. When flowing through the sinusoid, the nutrients are absorbed and further "processed" by hepatocytes and a part of them flows back into the bloodstream for body energy supply with the remainder stored for use when needed. ${ }^{1}$

Imbalanced glucose homeostasis in the liver causes metabolic syndromes (MSs), which are a combination of disorders including high blood pressure, high serum triglyceride level, impaired fasting glucose or insulin resistance, and so on. ${ }^{2} \mathrm{MS}$ is a high-risk factor for coronary heart disease, diabetes, stroke, hypertension and chronic liver diseases. ${ }^{3}$

Based on the promotion of weight loss and physical exercise, lifestyle modification is an effective method of improving mild and moderate MSs induced by imbalanced 
glucose homeostasis. ${ }^{4}$ For example, high dietary cholesterol together with high dietary fat can interact synergistically to develop hepatic steatosis, a reversible condition wherein a large amount of lipid droplets accumulate in liver cells, as well as its associated metabolic abnormalities. ${ }^{5}$ Moreover, chronic intake of Western-style diets, including fructose and/or fat, and alcoholic beverages also may induce hepatic damage, MSs and such accompanying diseases as nonalcoholic fatty liver disease, over time. ${ }^{6,7}$ However, some effective preventive approaches such as lifestyle changes, exercise, and adherence to Mediterranean diet can reduce the specific risk factors. ${ }^{8,9}$ Some target-based drugs have been developed for MS treatment, such as insulin sensitizing agent (metformin), peroxisome proliferator-activated receptor agonists (fibrates) and $\alpha$-glucosidase inhibitor (acarbose), which have produced significant effects in clinical trials.

From the molecular biology perspective, MS is characterized by an imbalance of the glucose homeostasis network with multiple pathogenic mechanisms and is not likely to result from one single target defect. Multitarget drugs have raised considerable interest regarding the regulation of imbalanced glucose homeostasis. Recently, a number of publications have indicated that it is necessary to expand drug development toward the multitarget approach for complex pathologies of systemic diseases. ${ }^{10,11}$ Compared with single-target medication, some multitarget approaches can synergistically act on multiple targets of diseases and thus may be more effective at controlling complex disease systems like MSs.

Some compounds isolated from natural medicines have been reported as regulators of glucose homeostasis with a multitarget manner. For example, 1-deoxynojirimycin, an alkaloid from mulberry leaves (Morus alba L., Moraceae), has been found to be an $\alpha$-glucosidase inhibitor with adiponectin enhancement, ${ }^{12} \beta$-oxidation activation and lipid accumulation inhibitory effects. ${ }^{13,14}$ Berberin, an alkaloid isolated from Rhizoma coptidis (Coptis chinensis Franch., Ranunculaceae), has shown regulating effects on abnormal lipid and glucose metabolism. The mechanism includes improving insulin resistance, ${ }^{15}$ promoting insulin secretion, ${ }^{16}$ inhibiting gluconeogenesis in the liver, ${ }^{17}$ stimulating glycolysis in peripheral tissue cells, ${ }^{18}$ and modulating gut microbiota. ${ }^{19}$ Curcumin, a phenolic compound isolated from Curcuma longa, has shown potential effects on glucose homeostasis through modulating oxidation stress status and inflammation cascades in a highfat-diet-induced MS model, ${ }^{20,21}$ as well as stimulating expression of nuclear factor $\mathrm{\kappa B}$ (inflammation-related transcription factor), TNF- $\alpha$, leptin and catalase.
In this review, we provide a summary of known roles on liver glucose homeostasis in human physiologic and pathophysiologic processes, summarize the potential bioactive compounds from natural products with medicinal value, and also focus on polypharmacologic and multitarget natural products related to various signaling pathways in hepatic glucose metabolism.

\section{Hepatic glucose utilization in normal and metabolically disturbed states}

The liver contributes to more than one third of the dietary glucose absorption after a meal. It maintains the glycemic control in a normal physiology by rapid clearance of glucose circulating in the blood through uptake, glycolysis and glycogen synthesis. However, in a state of metabolic disturbance, several major enzymes are abnormally expressed in the liver, and focusing on these targets is of great therapeutic significance in drug development.

\section{Hepatocyte glucose uptake}

Hepatocyte glucose uptake in normal state

Hepatic glucose uptake in normal state is mediated by three major factors, including the insulin concentration in the hepatic sinusoid, the signaling produced by the arterial-portal glucose gradient (portal signaling) and the distribution of the intraportally infused glucose to the liver (hepatic glucose load). In hepatocytes, the glucose transporter type 2 (solute carrier family 2, member A2, SLC2A2 or GLUT2) contributes predominantly to the human hepatic glucose uptake. The expression and activity of GLUT2 is transcriptionally regulated by peroxisome proliferator-activated receptor- $\gamma$ $(\text { PPAR- } \gamma)^{22}$ as well as hepatocyte nuclear factor (HNF)- $1 \alpha$, HNF-3 $\beta$ and HNF- $4 \alpha,{ }^{23-25}$ but is independent of insulin signaling. Moreover, glucokinase (GK) also has a close relationship with hepatic glucose uptake. In basal state (with a glucose concentration of about $5.5 \mathrm{mmol} / \mathrm{L}$ ), GK exists in the nucleus and is combined with glucose kinase regulatory protein (GKRP). When hepatocytes are exposed in hyperglycemia (with a glucose concentration of about $10-30 \mathrm{mmol} / \mathrm{L}$ ), GK is released and translocated into the cytoplasm to promote the glucose uptake and utilization (Figure 1).

\section{Hepatocyte glucose uptake in metabolically disturbed state}

Hepatic glucose uptake is impaired in MS patients, which is one of the reasons for postprandial hyperglycemia and may be induced by the impairment of some of the above regulation factors. In human subjects, the protein expression of GLUT2 


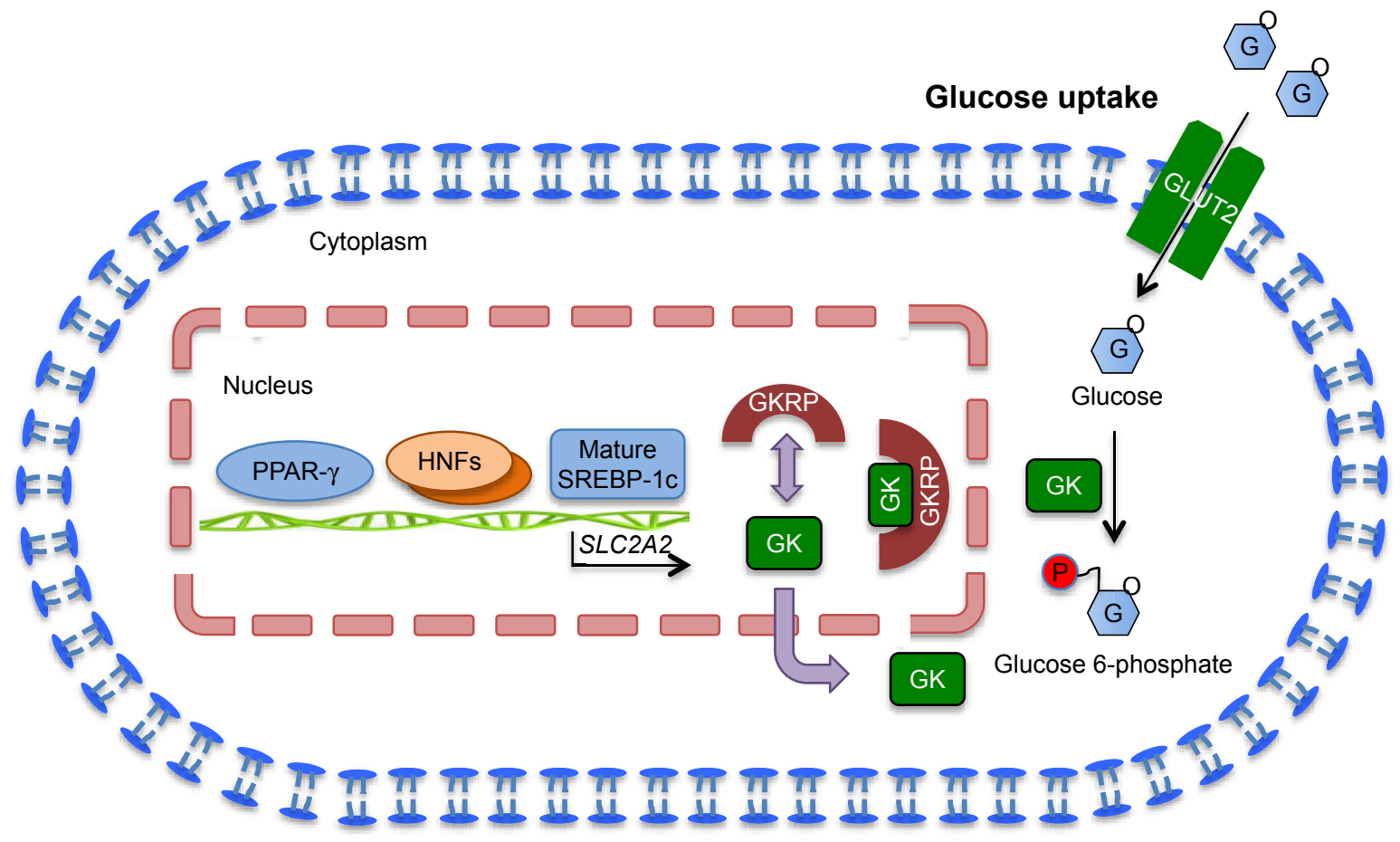

Figure I Regulation of hepatic glucose uptake.

Notes: Glucose absorbed in the small intestine is transferred from blood into hepatocytes by GLUT2, which is transcriptionally regulated by hepatocyte nucleus factor PPAR- $\gamma$ and HNFs. GK also contributes to the promotion of hepatic glucose uptake, which is competitively inhibited by binding with GKRP in the nucleus in basal state and is released and translocated into cytoplasm in hyperglycemic state. See the main text for more specific regulatory pathways.

Abbreviations: GK, glucokinase; GKRP, glucose kinase regulatory protein; HNF, hepatocyte nuclear factor; PPAR, peroxisome proliferator-activated receptor; SREBP-I c, sterol regulatory element-binding protein Ic.

is much higher in obese than that in lean subjects; however, obese patients with non-insulin-dependent diabetes do not show a further upregulation compared to obese controls in spite of their hyperglycemic status. ${ }^{26}$ The possible reason is that GLUT2 is a bidirectional transporter that also contributes to the transportation of glucose out of hepatocytes. While hepatic glucose uptake is also associated with many other factors including GK as the decrease of GK translocation in diabetic state would reduce the glucose uptake and therefore weaken the glucose disposal ability of the liver.

\section{GLUT2 inhibitors for glycemic control}

A number of studies suggest that overexpression of hepatic GLUT2 is found in many diabetic animals or cells. ${ }^{27-31}$ Using these models, some PPAR- $\gamma$ agonists, such as rosiglitazone and thiazolidinediones, have been reported to stimulate the release and synthesis of insulin in pancreatic $\beta$-cells through the upregulation of GLUT-2 and GK gene expressions, and they can also directly activate hepatic GK expression in primary hepatocytes, thereby improving glucose homeostasis in MS patients.

In recent years, some crude plant extracts have also been reported to reverse overexpression of GLUT2 or suppress its translocation from the cytoplasm to the plasma membrane in cases of MSs or hepatic steatosis. The representative plants include Ficus deltoidea (Moraceae) leaves, ${ }^{32}$ Ganoderma lucidum, ${ }^{33}$ Psidium guajava leaves, ${ }^{34}$ Symplocos cochinchinensi ${ }^{35}$ and Urtica dioica (stinging nettle) leaves. ${ }^{30}$

In addition to these crude plant extracts, more and more pure compounds have been found to produce similar effects, such as resveratrol, ${ }^{36,37}$ ankaflavin, ${ }^{38}$ curcumin,${ }^{39}$ ferulic acid ${ }^{40}$ and caffeic acid phenethyl estertaurine ${ }^{41}$ For example, ferulic acid, a phenolic acid isolated from Ferula assafoetida, can restore the elevated gluconeogenesis to a normal level in Wistar rats with high-fat diet, ${ }^{40}$ the mechanism of which involves downregulating hepatic GLUT2 expression and SREBP-1c, HNF- $1 \alpha$ and HNF- $3 \beta$ transcription factors.

\section{Hepatic glycolysis}

\section{Hepatic glycolysis in normal state}

Once taken up into hepatocytes, glucose is first phosphorylated by GK to yield glucose-6-phosphate. GK accounts for 95\% of glucose phosphorylation activity and is transcriptionally controlled by insulin and glucagon so that insulin increases the mRNA expression and activity of GK, whereas glucagon has the opposite effect. ${ }^{42}$ GKRP acts as a competitive 
inhibitor of glucose, binding to GK and sequestering the enzyme to the nucleus. ${ }^{43}$

Two other key rate-limiting enzymes in the liver of the 10-step glycolysis are phosphofructokinase-1 and liver-type pyruvate kinase M2. The former catalyzes the metabolically irreversible step that essentially converts fructose 6-bisphosphate into fructose 1,6-bisphosphate, and the latter catalyzes the final step of the process that converts phosphoenolpyruvate (PEP) into pyruvate. Both of the two kinases can be regulated by insulin, glucagon and epinephrine via protein kinase A (PKA) and the phosphoinositide-3-kinase $(\mathrm{PI} K \mathrm{~K}) /$ Akt pathway in the presence of glucose.

With food intake, in addition to the acute regulation of the above enzymes, glycolysis is also regulated by sterol regulatory element-binding protein 1c (SREBP-1c) and carbohydrate response element binding protein (ChREBP). Recent studies have indicated the involvement of various kinases in the control of SREBP-1c and ChREBP activities. PKA is shown to mediate the negative regulatory effect of glucagon on SREBP-1. ${ }^{44}$ AMP-activated protein kinase (AMPK) blocks proteolysis and nuclear localization of SREBP-1c, ${ }^{45}$ while AMPK-related salt-inducible kinase 1 (SIK1) directly reduces its transcriptional activity. ${ }^{46}$ In addition, liver $\mathrm{X}$ receptor $\alpha(\mathrm{LXR} \alpha)$ and $\mathrm{C} / \mathrm{EBP}-\beta$ also contribute to the transcription of SREBP-1c. ${ }^{47}$ Likely, for ChREBP, PKA is critical for its cellular localization $^{48}$ and AMPK is important for its DNA binding ability (Figure 2). ${ }^{49}$

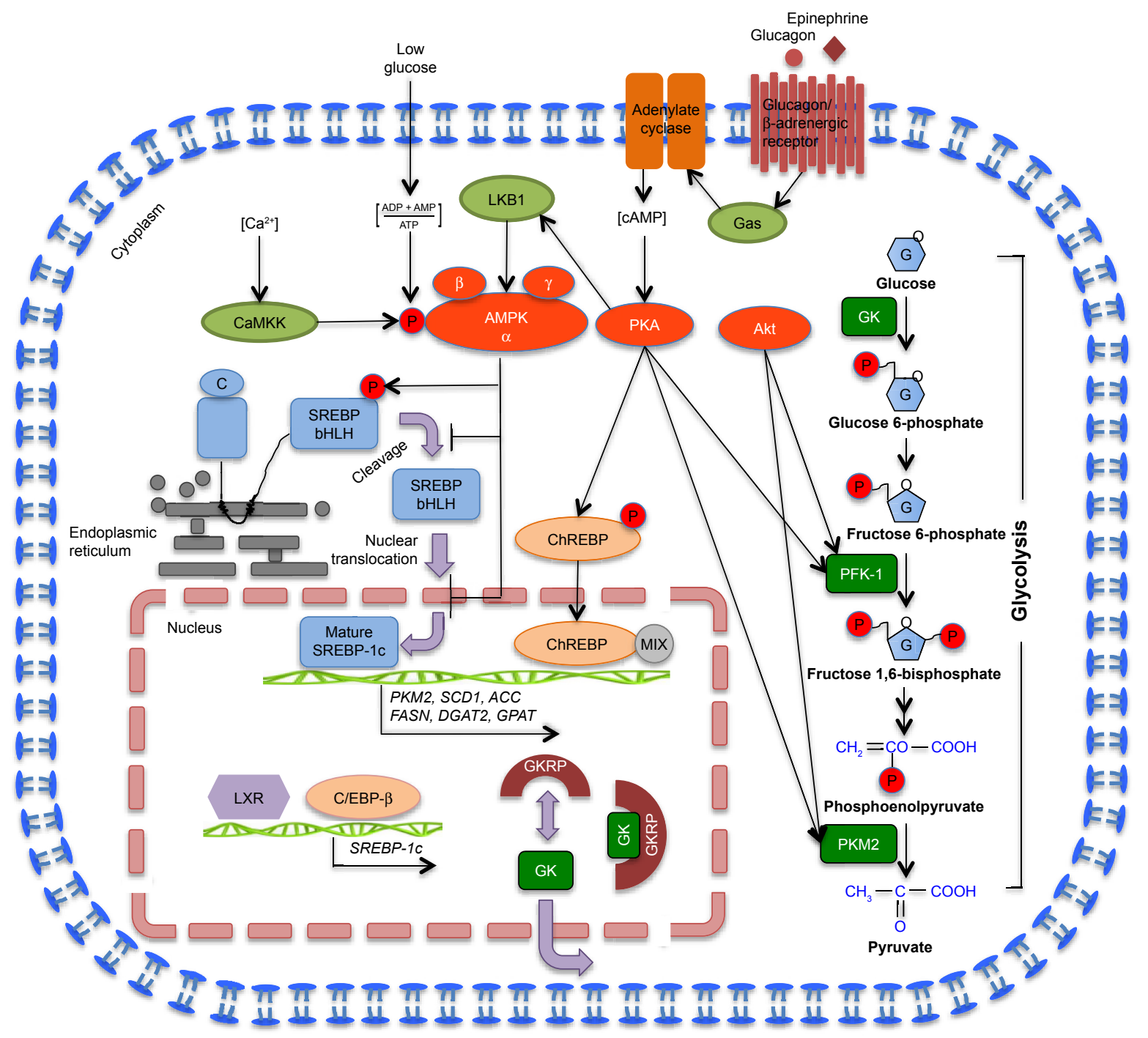

Figure 2 Regulation of hepatic glycolysis.

Notes: The absorbed glucose undergoes the glycolysis process that is catalyzed by three major enzymes, GK, PFK-I and PKM2, successively, to generate pyruvate. The last two kinases are regulated by hormones via PKA and Akt in the presence of glucose and transcriptionally regulated by SREBP-Ic and ChREBP. See the main text for more specific regulatory pathways.

Abbreviations: AMPK, AMP-activated protein kinase; cAMP, cyclic adenosine monophosphate; ChREBP, carbohydrate response element binding protein; GK, glucokinase; PFK-I, phosphofructokinase-I; PKA, protein kinase A; PKM2, pyruvate kinase M2; SREBP-Ic, sterol regulatory element-binding protein Ic. 
Hepatic glycolysis in metabolically disturbed state In patients with hepatopathy, activities of enzymes involved in glycolysis and the Krebs cycle are significantly decreased, which results in a decline of regulatory functions. If insulin resistance and insulin secretion or metabolism dysfunction also coexist, it is more likely to develop into hepatic diabetes. ${ }^{50}$ In diabetic state, the hepatic deactivation effect on insulin agonist, glucagon and catecholamines is decreased. And, with the reduction of the insulin/glucagon ratio, hepatic glycolysis is difficult to trigger, causing an obstacle for glucose utilization. In addition, although total GK is probably decreased in the pancreas, the $\beta$-cell GK has been strongly proved to be functional. However, the hepatic GK expression is quite different and may be greatly reduced because of its insulin-dependent manner. ${ }^{51,52}$

\section{Liver-specific GK activators for glycemic control}

Activation of GK has potential effects both in the pancreas and in the liver, which would have a significant effect on circulating glucose levels in the diabetic state. However, targeting the pancreas would ultimately result in a worsening of the diabetic state because it would not only result in hypoglycemia but also lead to more profound $\beta$-cell failure. For this reason, a liver-selective GK activator is a safer and more effective antidiabetic agent compared to the pancreastargeted one.

In the past few years, a number of small-molecule synthetic GK activators have been found, ${ }^{53}$ and Phase II trials of some GK activator drugs are now underway, such as for AZD-1656, AZD-6379, TTP-399, PF-04937319, GKM-001 and GK1-399. However, some of them have been identified as having poor druggability because of their low hepatic selectivity and unexpected side effects.

Many crude extracts of natural plants have been proved to have mild yet compelling effects on enhancing hepatic GK activity and restoring liver glycogen, such as Polygonatum kingianum,$^{54}$ Ventilago maderaspatana, ${ }^{55}$ Ulva fasciata ${ }^{56}$ Phyllanthus amarus ${ }^{57}$ as well as Achyranthes aspera ${ }^{58}$ and Artemisia sphaerocephala. ${ }^{59}$ For example, total saponins from Polygonatum kingianum were found to control blood glucose in streptozotocin-induced diabetic rats via upregulating the expression of GLUT4, PPAR- $\gamma$, AMPK and hepatic GK as well as downregulating the expression of G6P to promote not only glycogenesis but also glucose utilization. Nonetheless, findings on effective pure natural compounds are so far limited. Known effective compounds include tatanans A-C from Acorus tatarinowii plants ${ }^{60}$ and four bioactive ingredients in mulberries (1-deoxynojrimycin, resveratrol, cyanidin-3-glucoside and cyanidin-3-rutinoside). ${ }^{61}$
Thus, natural products as promising entities for GK activators have immense potential to be investigated in the future.

\section{Hepatic glycogen synthesis}

Hepatic glycogen synthesis in normal state

In the abundant glucose condition, the redundant glucose-6phosphate is converted into uridine diphosphate glucose and then glycogen synthesis starts with the catalysis of glycogen synthase (GYS). GYS is phosphorylated and thus inactivated in a very complex and insufficiently characterized manner involving multiple phosphorylation sites and by several kinases including AMPK, PKA and glycogen synthase kinase 3 (GSK-3). GSK-3 is a downstream target of PI3K/ Akt and thus insulin signaling cascades. In addition, GYS can also be dephosphorylated and subsequently activated by protein phosphatase-1, which is considered to be involved in the mechanism of insulin-enhanced glycogen synthesis in the liver (Figure 3).

\section{Hepatic glycogen synthesis in metabolically disturbed state}

In healthy subjects, about $50 \%$ of the glucose is stored as glycogen after a meal, whereas in patients with impaired glucose tolerance, the ability to store glucose is reduced. ${ }^{62}$ As the hepatic capacity to store glycogen is limited, the excess dietary glucose is used to synthesize fat by hepatic de novo lipogenesis in the carbohydrate overfeeding condition. ${ }^{63}$ The risk of hepatic lipid accumulation is thus increased. Moreover, in the development of MSs, dysregulation of GSK-3 has been reported to be involved and the two isoforms, GSK-3 $\alpha$ and GSK-3 $\beta$, play distinct and tissue-specific roles in this pathologic process. ${ }^{64}$ In nonalcoholic steatohepatitis subjects or diet-induced obesity and MS rat models, the expression of the insulin receptor and insulin receptor substrate-1/2 (IRS-1/2) is also markedly reduced, which subsequently induces the impairment of insulin signaling and inhibition of glycogen synthesis. ${ }^{65,66}$

\section{GSK-3 inhibitors for glycemic control}

Substantial evidence has demonstrated the linkage between GSK-3 and the development of MSs. ${ }^{62,67,68}$ A strategy of GSK-3 inhibition for the treatment of MSs should hence be designed. Although dysregulation of GSK-3 is also involved in many other diseases including Alzheimer's disease, bipolar disorder and cancer, many chemical GSK-3 inhibitors have been described and verified as potent agents in enhancing the hepatic GS activity. ${ }^{69}$

To our knowledge, in natural products, direct GSK-3 inhibitors have been rarely reported, but a number of natural 


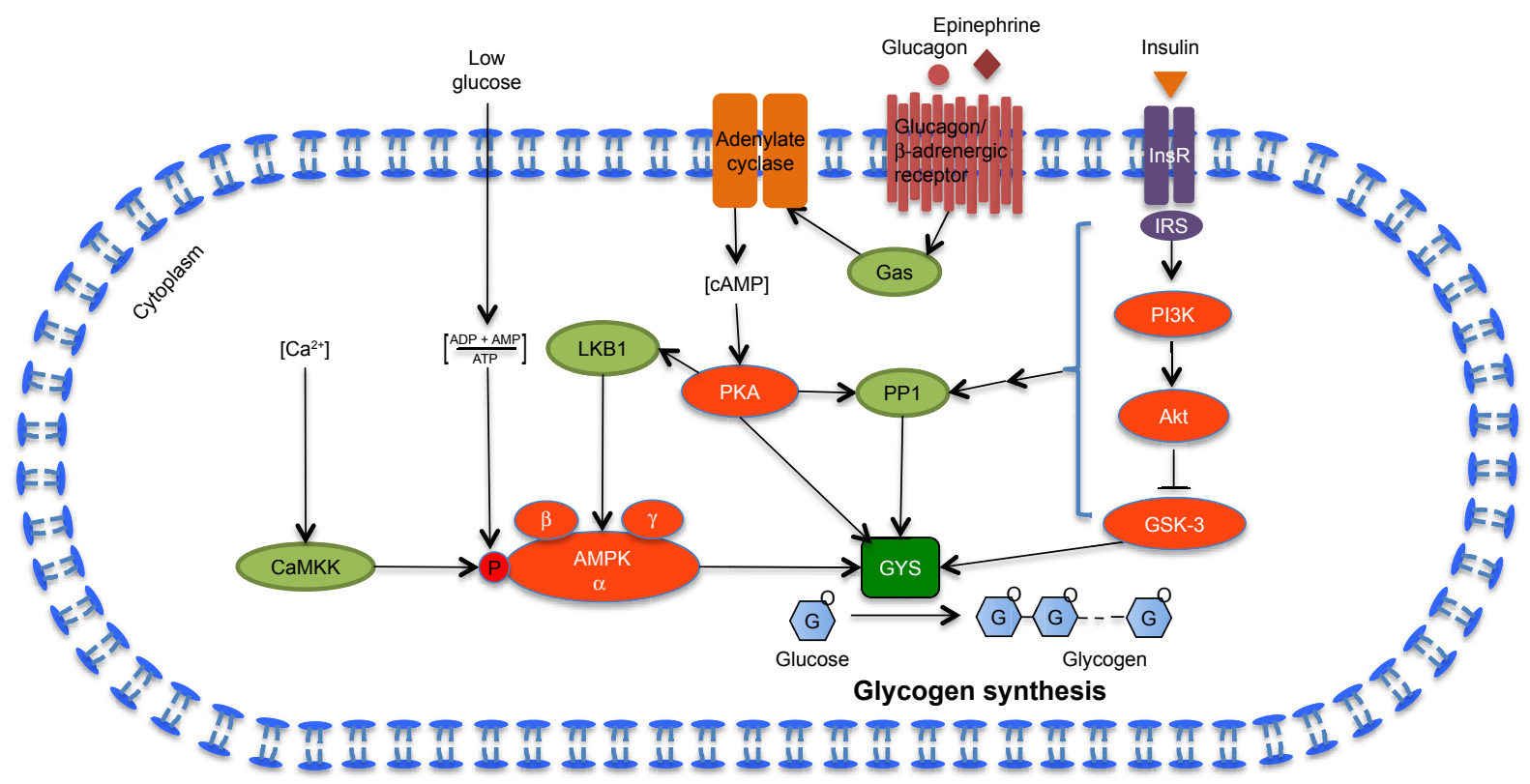

Figure 3 Regulation of hepatic glycogen synthesis.

Notes: When glucose is abundant, glucose is stored in the form of glycogen catalyzed by GYS, which is mainly regulated by AMPK, PKA and PI3K/Akt pathways. See the main text for more specific regulatory pathways.

Abbreviations: AMPK, AMP-activated protein kinase; GYS, glycogen synthase; PI3K, phosphoinositide-3-kinase; PKA, protein kinase A.

products can indirectly promote glycogen synthesis through PI3K/Akt-mediated GSK-3 phosphorylation. These compounds include epigallocatechin-3-gallate (EGCG) from green tea, ${ }^{70}$ nigelladines A-C from the seeds of Nigella glandulifera,${ }^{71}$ as well as ursolic acid and luteolin-7-glucoside present in many plants particularly abundant in the Salvia species. ${ }^{72}$

\section{Hepatic production in normal and metabolically disturbed states}

When nutrients become scarce, the liver releases glucose into the bloodstream by two pathways, glycogen breakdown (glycogenolysis) and glucose de novo synthesis (gluconeogenesis). High fasting glucose levels are warning signs of MSs, one of the causes being overproduction of hepatic glucose. Some listed hypoglycemic drugs, such as metformin, glyburide and pioglitazone, inhibit hepatic glucose overproduction. In addition, many crude plant extracts and natural products also exhibit similar effects. ${ }^{73-75}$

\section{Hepatic glycogenolysis and gluconeogenesis in normal state}

During the period of short-term fasting, glycogenolysis is the predominant glucose source and glycogen polymer degradation is catalyzed by glycogen phosphorylase (GP) through unfastening the $\alpha-1,4$-glycosidic bonds and liberating glucose 1-phosphate, which can be converted into glucose 6-phosphate by phosphoglucomutase. Glucose 6-phosphate is then further converted into glucose by glucose 6-phosphatase (G6Pase) or incorporated into glycolysis depending on the energy status. GP is regulated via phosphorylation by PKA, which can be inhibited by insulin and gene expression of G6Pase that is induced by both hyperglycemia and by insulin deficiency.

Following prolonged periods of fasting, glycogen reserve is gradually consumed and gluconeogenesis becomes the predominant source. Some precursors, such as pyruvate, lactate, alanine and glycerol, are used for hepatic glucose de novo synthesis (Figure 4). Gluconeogenesis can be briefly described as a two-stage process: first, the precursors (excluding glycerol) are converted into oxaloacetate catalyzed by pyruvate carboxylase (PC) and then into PEP by phosphoenolpyruvate carboxykinase; secondly, PEP is converted into fructose 6-phosphate catalyzed by fructose 1,6-bisphosphatase (FBPase) and further generates glucose catalyzed by G6Pase. The chronic activation of gluconeogenesis is controlled by several major transcriptional factors including cAMP responsive element binding protein (CREB) and CREB-regulated transcription coactivator (TORC)-2, peroxisome proliferator-activated receptor gamma co-activator 1 alpha and forkhead box O1 (Figure 5).

\section{Hepatic glycogenolysis and gluconeogenesis in metabolically disturbed state}

In the diabetic state, the liver becomes resistant to insulin and the hepatic glucose production is consequently increased 


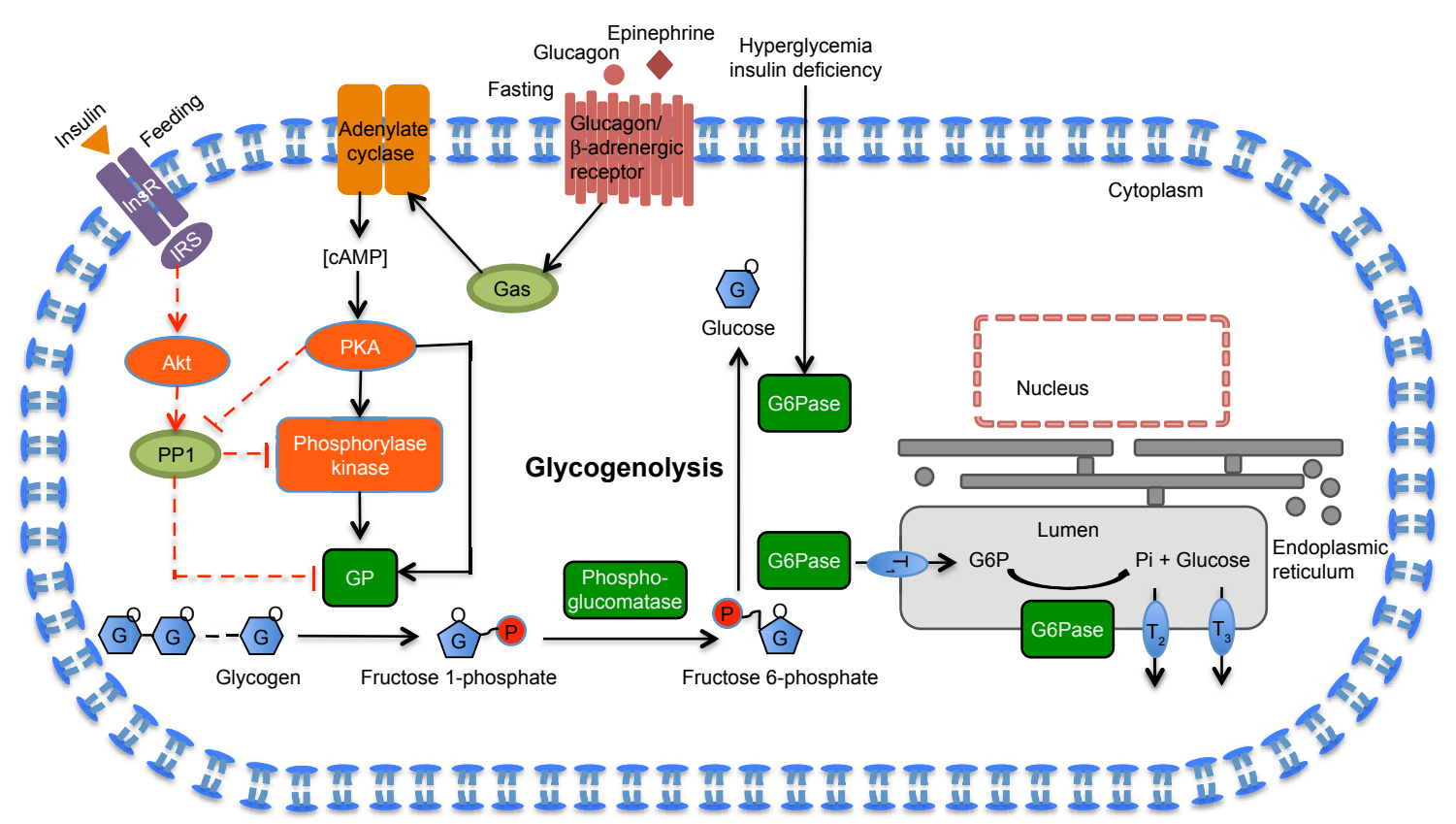

Figure 4 Regulation of hepatic glycogenolysis.

Notes: Under fasting condition, hepatic glycogenolysis is enhanced via an increased concentration of glucagon and epinephrine. GP, phosphoglucomatase and G6Pase are critical in coordinating the fasting-mediated activation of glycogenolysis. The solid black line represents the pathway under fasting condition and the red dotted line the feeding condition. See the main text for more specific regulatory pathways.

Abbreviations: G6Pase, glucose 6-phosphatase; GP, glycogen phosphorylase; PKA, protein kinase A.

in MS patients, which contributes to the postprandial hyperglycemia. The changes in expressions of proteins involved in glucose metabolism, resulting from chronic hyperglycemia, would further aggravate the metabolic imbalance, which is described as "glucose toxicity". For example, elevated hepatic GP and G6Pase activity occurs in hyperglycemic conditions, which are responsible for the impaired glycogen synthesis. Hyperglycemia promotes the elevation of GP and G6Pase, which in turn leads to further increases in glucose production. Moreover, G6Pase catalyzes the terminal steps in both the processes. However, levels of the G6Pase catalytic protein, whose active site locates at the luminal side of the endoplasmic reticulum, and the expressions of $\mathrm{T}_{1}$-translocase, a specific transporter that mediates the entry of G6Pase into the luminal compartment, $\mathrm{T}_{2}$-translocase, which mediates the export of inorganic phosphate back to the cytosol, and $\mathrm{T}_{3}$-translocase, which mediates the export of glucose back to the cytosol, have been shown to be dysregulated in diabetes. ${ }^{76-78}$

\section{GP inhibitors for glycemic control}

Inhibiting overproduction of hepatic glucose is one of the major mechanisms of many listed hypoglycemic drugs, such as metformin, glyburide and pioglitazone. However, they are not direct inhibitors of hepatic GP. Although a direct GP inhibitor, nitrogen heterindoleamide derivative PSN-357, has been tested in Phase II study, ${ }^{143}$ which found that it is difficult to develop this drug into a liver selective type. In fact, inhibiting the activity of GP to prevent unwanted glycogenolysis is an effective way for glycemic control.

GP has at least five different ligand-binding sites that might prevent glycogenolysis under high glucose levels, and so far dozens of natural product inhibitors have been identified. Some iminosugars that bind to the catalytic site of GP, such as 1,4-dideoxy-1,4-imino-D-arabinitol, as well as isofagomine and its derivative have been reported as potent inhibitors of liver GP and of basal and glucagon-stimulated glycogenolysis. ${ }^{79,80}$ Flavonoids (including quercetin, chrysin and flavopiridol), indirubins and catechin gallates that bind to the inhibitor site ${ }^{81-83}$ as well as pentacyclic triterpenes that bind to the allosteric site ${ }^{84}$ have been revealed as inhibitors of GP at micromolar levels. Consequently, binding to the allosteric site of GP also may be one of the possible antidiabetic mechanisms of certain active plants rich in flavonoids.

\section{G6Pase inhibitors for glycemic control}

It is possible that pharmacologic inhibitors targeting the G6Pase will likely inhibit other phosphatases, thus leading to undesirable consequences. However, G6Pase translocases are more rational targets for pharmacologic intervention 


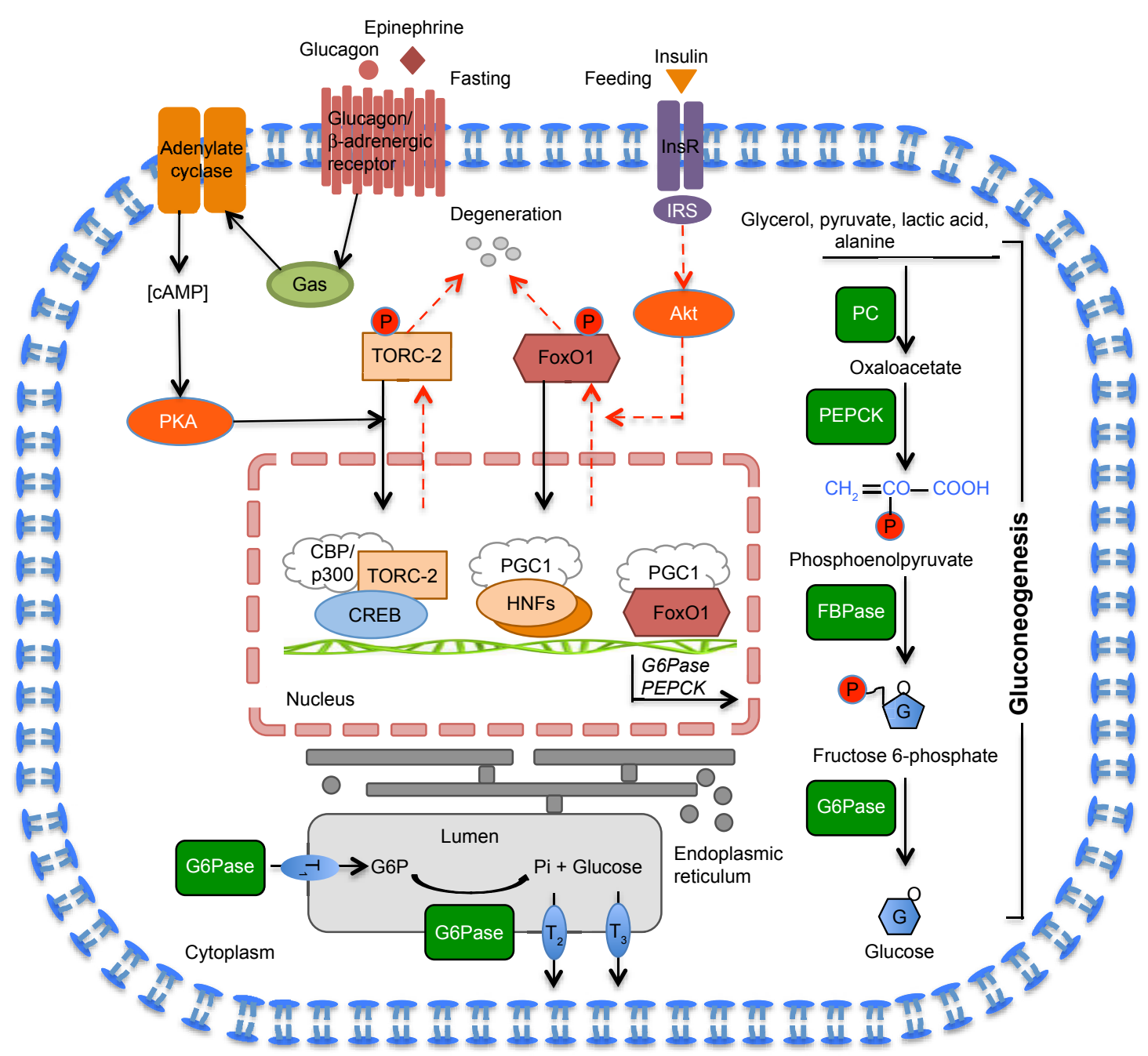

Figure 5 Regulation of hepatic gluconeogenesis.

Notes: In prolonged fasting, hepatic gluconeogenesis is initiated and catalyzed by a series of enzymes including PC, PEPCK, FBPase and G6Pase. With food intake, the hepatic glucose production pathways are inhibited by the activation of insulin-mediated PI3K/Akt pathway. CREB/TORC-2, HNFs, FoxOI and a family of nuclear receptors are critical in the activation of hepatic glucose production. The solid black line represents for the pathway under fasting condition and the red dotted line for the feeding condition. See the main text for more specific regulatory pathways.

Abbreviations: FBPase, fructose I,6-bisphosphatase; FoxOI, forkhead box OI; G6Pase, glucose 6-phosphatase; HNF, hepatocyte nuclear factor; PC, Pyruvate carboxylase; PEPCK, phosphoenolpyruvate carboxykinase; PI3K, phosphoinositide-3-kinase; PKA, protein kinase A; TORC-2, CREB and its co-activator 2.

because they are structurally distinct and catalyze the slow step of glucose production.

The known G6Pase inhibitors can be placed into two categories: catalytic protein inhibitors and inhibitors of $\mathrm{T}_{1}-, \mathrm{T}_{2}-$ and $\mathrm{T}_{3}$-translocase. Among these inhibitors, some natural products such as chlorogenic acid ${ }^{85}$ exhibited high inhibitory affinities to the translocase sites, and is a secondary metabolite of many plants, phloretin and phlorizin, ${ }^{86}$ which are the principal phenolic components of apple trees, flavonoids from Bauhinia megalandra leaves, ${ }^{87}$ as well as many products of fungi or bacteria, ${ }^{88}$ including kodaistatin, anthraquinones, mumbaistatin and thielavins. In addition, it is reported that extracts of some plants also inhibit the transcriptional expression or activity of G6Pase, and include mulberry branch bark extract, ${ }^{89}$ aqueous extract of Clitocybe nuda $a^{90}$ and methanolic extract of Ventilago maderaspatana..$^{55}$

\section{Multitarget approach of natural products used to act on hepatic glucose homeostasis}

Dysregulation of hepatic glucose metabolism is comprised of complex mechanisms, and according to the abnormally changed enzymes in the metabolically disturbed state (Table 1), a series of pertinent drugs or predrugs have been discovered or developed. Natural products have been widely accepted to be the source of most active ingredients in many medicines. In the recent decade, substantial efforts have been made to discover 
Table I Major changes under metabolically disturbed state compared with normal state in the liver

\begin{tabular}{ll}
$\begin{array}{l}\text { Hepatic glucose } \\
\text { metabolism }\end{array}$ & $\begin{array}{l}\text { Major changes under metabolically } \\
\text { disturbed state compared with } \\
\text { pormal state in the liver }\end{array}$ \\
\hline Glucose uptake & $\begin{array}{l}\text { GLUT2 expression is downregulated } \\
\text { GK translocation is decreased } \\
\text { Ratio of insulin and glucagon is reduced }\end{array}$ \\
Glycolysis & GK expression is reduced \\
GSK-3 is upregulated \\
Glycogen synthesis & IRS-1/2 expression is reduced \\
Glycogenolysis and & GP activity is elevated \\
gluconeogenesis & G6Pase activity is increased \\
& Transporters of G6Pase are upregulated
\end{tabular}

Abbreviations: G6Pase, glucose 6-phosphatase; GK, glucokinase; GSK-3, glycogen synthase kinase 3; IRS-I, insulin receptor substrate I.

novel compounds, which can be applied therapeutically in the treatment of MSs. A number of natural pure compounds and crude extracts have been made available for glycemic control with different mechanisms of action, an important proportion of which are in the multitarget approach.

Several decades ago, drug development was only focused on a limited number of crucial targets for diseases. However, with the increasing concern of the drawbacks of single-target drugs, such as single regulation linkage, low clinical efficacy, high risks of side effects, and strong drug resistance, "combination therapy" emerged, though the shortcomings mentioned above were not truly solved. In contrast, multitarget natural products are now becoming common and exhibit distinct advantages, especially in the treatment of complex and chronic diseases like MSs. Some of the most studied potential antidiabetic natural products with privileged structures are quercetin, resveratrol, EGCG, curcumin, berberin and salicylat. For example, berberin is an antimicrobial isoquinoline plant alkaloid present in many plants such as Berberis vulgaris, C. chinensis and Berberis aristata, and it also possesses some other pharmacologic properties including antitumoral, glucose- and cholesterol-lowering as well as immune-modulatory activities. With regard to its hypoglycemic effect, the direct molecular targets of berberin are AMPK, ${ }^{18}$ PPARs, ${ }^{91}$ ERK,,${ }^{92}$ PKC $^{93}$ and glucagon-like peptide-1 (GLP-1) ${ }^{94}$ (Table 2). The downstream targets that are directly involved in glucose metabolism are subsequently regulated to achieve the glycemic control. In addition, the regulation of berberin is a multitissue process involving the liver, muscle, adipose tissue, pancreas and small intestine. Through the multiple regulation linkage, berberin exhibits stable and safe effects on experimental and clinical glycemic control.

\section{Discussion}

The liver plays an important role in the regulation of glucose metabolism. Glucose homeostasis disorder is a risk factor for diabetes, heart disease and stroke. Several medications are used to regulate glucose homeostasis. For example, metformin, which is commonly used to improve fasting hepatic insulin sensitivity and reduce hepatic glucose production. Glyburide, a kind of sulfonylurea, decreases glucose production and enhances insulin action in the liver. ${ }^{128}$ Pioglitazone, a kind of thiazolidinedione, improves hepatic insulin sensitivity and reduces hepatic glucose production.

Recently, current medication treatments appear to be ineffective or contraindicated in growing numbers of patients, and as a result, difficult-to-treat diseases require alternative therapies. According to pathophysiologic research results, the pharmaceutical industry has promoted the development of innovative therapies on novel targets involved in liver glucose metabolism. The GK activators, PF-04937319 and GKM-001, have been developed by Pfizer Inc. and Advinus Therapeutics Ltd., respectively. PSN-357, a GP inhibitor with a nitrogen heterindoleamide structure, has been developed by OSI Pharmaceuticals Inc. PTP1B inhibitor, ISIS-PTP-1BRx (Isis Pharmaceuticals Inc.) and TTP-814 (TransTech Pharma Inc.) have completed Phase II trials. Liver-specific GK activator, GSK-3 inhibitor, GP inhibitor, FBPase inhibitor, G6Pase inhibitor, PTP1B inhibitor and FFAR1 activator are becoming hotspots in target-based new drug development.

Lead compound from natural products is one of the most important resources for developing new drugs. Generally, natural products have less activity and nonselectivity compared with synthesized compounds. For example, in the discovery of GK activator, the half maximal effective concentration $\left(\mathrm{EC}_{50}\right)$ of synthesized activator TMG-123 was $<1 \mu \mathrm{M},{ }^{129}$ while to our knowledge, the best $\mathrm{EC}_{50}$ of the natural product, mangiferin (a xanthone glucoside from the leaves of Mangifera indica and the root of Anemarrhena asphodeloides), was more than $100 \mu \mathrm{M} .{ }^{130}$ In addition to GK activation activity, mangiferin has various other functions via diverse targets, such as antioxidant, antimicrobial, antidiabetic, antiallergic and anticancer, ${ }^{131}$ which exhibits its nonselective characteristic feature.

The problem of less activity of natural products can be solved by chemical structural modification. In the early 20th century, researchers isolated a guanidine named galegine from Galega officinalis which belongs to the Fabaceae family, with weak antidiabetic activity. After structural modification, a series of biguanides were synthesized, and finally, metformin was developed as an "elixir" for clinical 
Table 2 Major targets and mechanisms of several antidiabetic multitarget natural products: quercetin, resveratrol, EGCG, curcumin and berberin

\begin{tabular}{|c|c|c|c|}
\hline $\begin{array}{l}\text { Compound (mode } \\
\text { of action in the liver) }\end{array}$ & Molecular targets & Target tissue & Refs \\
\hline Quercetin & $\alpha$-glucosidases & Small intestine & 95 \\
\hline (promoted hepatic & GLUT2 & Small intestine & 96 \\
\hline glycolysis and glycogen & Glucokinase & Liver & 97 \\
\hline \multirow[t]{8}{*}{ synthesis) } & Glucose-6-phosphate & Liver & 97 \\
\hline & PI3K/Akt signaling & Liver & 98 \\
\hline & Glycogen synthase & Liver & 99 \\
\hline & AMPK/SIRTI signaling & Adipose & 100 \\
\hline & AMPK/GLUT4 signaling & Adipose/muscle & 99,101 \\
\hline & Insulin receptor, PTPIB & Adipose & 102 \\
\hline & TNF- $\alpha /$ PPAR- $\gamma$ signaling & Adipose & 102 \\
\hline & ERKI/2 signaling/insulin secretion & Pancreas & 103 \\
\hline Resveratrol & GLUT2 & Liver & 104 \\
\hline (promoted hepatic & SIRTI/PEPCK (G6Pase) & Liver & 105 \\
\hline glucose uptake, & FoxOI/PEPCK (G6Pase) & Liver & 105 \\
\hline suppressed hepatic & FoxOI/glucokinase signaling & Liver & 106 \\
\hline glycogenolysis and & HNF-4/glucokinase signaling & Liver & 106 \\
\hline \multirow[t]{4}{*}{ gluconeogenesis) } & AMPK/SIRTI signaling & Liver/muscle/adipose & 107,108 \\
\hline & AMPK/GLUT4 signaling & Muscle & 107 \\
\hline & PI3K/Akt signaling & Muscle & 109 \\
\hline & PGC-I $\alpha$ & Adipose tissue & 110 \\
\hline EGCG & $\alpha$-glucosidases & Small intestine & 83 \\
\hline (promoted hepatic & PEPCK, HNF-I, HNF-4 & Small intestine & III \\
\hline glycolysis, suppressed & Glycogen phosphorylase & Liver & 83 \\
\hline hepatic glycogenolysis & LKBI/AMPK/IRS-I signaling & Liver & 112 \\
\hline \multirow[t]{7}{*}{ and gluconeogenesis) } & PI3K/Akt/GSK-3ß signaling & Liver & 112 \\
\hline & IRS-I/PEPCK signaling & Liver & 113 \\
\hline & IRS-I/G6Pase signaling & Liver & 113 \\
\hline & AMPK/GLUT4 signaling & Muscle/adipose & 114,115 \\
\hline & PI3K/Akt/GLUT4 signaling & Muscle/adipose & 114,115 \\
\hline & Glutamate dehydrogenase & Muscle/pancreas & 116 \\
\hline & Inducible nitric oxide synthase & Muscle/pancreas & 117,118 \\
\hline Curcumin & $\alpha$-amylase & Serum & 119 \\
\hline (suppressed hepatic & GSK-3 $\beta$ & Liver & 120 \\
\hline glycogenolysis and & AMPK/PEPCK (G6Pase) signaling & Liver & 121 \\
\hline \multirow[t]{3}{*}{ gluconeogenesis) } & PPAR- $\gamma$ & Liver/adipose & 122,123 \\
\hline & AMPK/p-38 MAPK signaling & Muscle & 124 \\
\hline & AMPK/GLUT4 signaling & Muscle & 125 \\
\hline Berberin & PEPCK, G6Pase & Liver & 126 \\
\hline (suppressed hepatic & FoxOI, SREBPI, ChREBP & Liver & 126 \\
\hline glycogenolysis and & PKC/IR signaling & Liver & 93 \\
\hline \multirow[t]{5}{*}{ gluconeogenesis) } & PPAR- $\alpha / \delta / \lambda$ & Liver & 91 \\
\hline & AMPK/GLUT4 signaling & Muscle/adipose & 18 \\
\hline & ERK/GLUTI signaling & Adipose & 92 \\
\hline & $\beta$ cell regeneration & Pancreas & 127 \\
\hline & Glucagon-like peptide-I secretion & Small intestine & 94 \\
\hline
\end{tabular}

Abbreviations: AMPK, AMP-activated protein kinase; ChREBP, carbohydrate response element binding protein; EGCG, epigallocatechin-3-gallate; FoxOI, forkhead box OI;

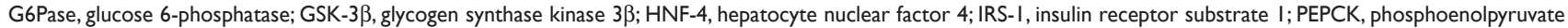
carboxykinase; PGC-I $\alpha$, peroxisome proliferator-activated receptor gamma co-activator I alpha; PI3K, phosphoinositide-3-kinase; PPAR, peroxisome proliferator-activated receptor.

MS management. ${ }^{132}$ Now, it has been proved that metaformin is a unique diabetes management drug with prevention of diabetic macrovascular complications. ${ }^{133}$

Nonselectivity of natural products is a weak point in target-based new drug development. However, it is an advantage point for multitarget disease treatment. As described in the introduction, MS is characterized by an imbalance of the glucose homeostasis network with multiple pathogenic mechanisms. Multitarget drugs have raised considerable interest regarding the regulation of imbalance of glucose 
homeostasis. Berberin, an alkaloid isolated from C. chinensis (Ranunculaceae), showed potential regulatory effect on MSs, and the mechanism was revealed to be partly related to AMPK, PI3K, AKT, TNF- $\alpha$, NF- $\kappa$ B, GLP-1, GLUT4, PPAR- $\gamma$, and so on. ${ }^{134}$ This phenomenon may be attributed to its planar structure of tricycle rings with a quaternary ammonium group, which is flexible enough to bind with ligands, but does not exhibit significant selectivity. With regard to its multitarget manner, berberine exhibited significant regulatory effects on glucose homeostasis. ${ }^{135}$

Multitarget drugs can be divided into two types, onecompound-multitarget and multicompound-multitarget. Generally, most compounds can interact with more than one target, including target-based synthesized compounds. This one-compound-multitarget characteristic is less beneficial for drug development; it sometimes leads to a loss of higher efficacy and an increase in the undesirable risks of toxicity and side effects. Multicompound-multitarget drugs are another direction of development methods for complex diseases. This strategy has been successfully used in MS clinical trials and achieved the goal of regulation. ${ }^{136}$

In management of MSs, the traditional Chinese medicine (TCM) is an excellent representative therapy in alternative and complementary medicines. ${ }^{137}$ Fang Feng Tong Sheng San, a preparation composed of 18 medicinal plants, has been shown to exert antiobesity, antidiabetes and lipid-lowering activities ${ }^{138}$ in clinical trials and laboratory experiments, and was used in China, Japan and Korea as an over-the-counter drug. Our previous study reported that Tangzhiqing formula, containing red peony root, mulberry leaf, lotus leaf, Danshen root and hawthorn leaf, upregulated PI3K, AKT, GYS and their phosphorylation, as well as GLUT4. ${ }^{139}$ Jinqi formula, containing Coptidis Rhizoma, Astragali Rhadix and Lonicerae japonicae Flos, showed inhibitory effects on triglyceride accumulation in the treatment of diabetes and obesity, and the mechanism was confirmed at least in part via the stimulation of AMPK activity in a multitarget manner. ${ }^{140}$

Clinical evidence of TCM formulas provides an indication of multicompound-multitarget type drug development. At least, on the basis of further therapy mechanisms and active material research, the results can offer an appropriate combination of compounds and a rational dose proportion. On the other hand, the comparison of different TCM formulas for MSs will lead to an understanding of key targets working in the MS network, and the identification of new therapeutic targets.

One TCM formula contains many kinds of compounds. Drug-target network screening will yield an immense amount of data, which will require warehouse-scale computing and sophisticated algorithms. ${ }^{141}$ Network pharmacology is a systematic biologic methodology for network analysis and drug design, which can illustrate the interactions between active compounds and multiple targets. ${ }^{142}$ More new systematic technologies are potentially useful for studying the action mechanisms of traditional natural medicines to develop valuable multitarget lead compounds from natural products for structural optimization with proven preclinical and clinical evidence in MS treatment.

Oriental medicine is a system of health care based on improving overall body function, while Western medicine has achieved great successes in target therapy. Combining the clinically effective oriental multicompound-multitarget drugs with the achieved Western study methods, and focusing on the clinical effects for the development of new drugs for MSs will be an integrated way to achieve benefits for all humanity.

\section{Acknowledgments}

This research was supported by the National Natural Science Foundation of China (81673703; 81173524), Important Drug Development Fund, Ministry of Science and Technology of China (2017ZX09305-002), and the Science and Technology Program of Tianjin, China (grant numbers 15PTCYSY00030 and 16ZXHLGX00170).

\section{Disclosure}

The authors report no conflicts of interest in this work.

\section{References}

1. Alwahsh SM, Ramador G. How does bariatric surgery improve type II diabetes? The neglected importance of the liver in clearing glucose and insulin from the portal blood. J Obesity Weight Loss Ther. 2015; $5(5): 1-4$

2. Alberti KG, Zimmet P, Shaw J. Metabolic syndrome-a new world-wide definition. A Consensus Statement from the International Diabetes Federation. Diabet Med. 2006;23(5):469-480.

3. Alberti KGM, Zimmet P, Shaw J. The metabolic syndrome-a new worldwide definition. Lancet. 2005;366(9491):1059.

4. Orchard TJ, Temprosa M, Goldberg R, et al. The effect of metformin and intensive lifestyle intervention on the metabolic syndrome: the diabetes prevention program randomized trial. Ann Intern Med. 2005;142(8): 611-619.

5. Savard C, Tartaglione EV, Kuver R, et al. Synergistic interaction of dietary cholesterol and dietary fat in inducing experimental steatohepatitis. Hepatology (Baltimore, Md). 2013;57(1):81-92.

6. Alwahsh SM, Xu M, Schultze FC, et al. Combination of alcohol and fructose exacerbates metabolic imbalance in terms of hepatic damage, dyslipidemia, and insulin resistance in rats. PLoS One. 2014;9(8): e104220.

7. Sellmann C, Priebs J, Landmann M, et al. Diets rich in fructose, fat or fructose and fat alter intestinal barrier function and lead to the development of nonalcoholic fatty liver disease over time. J Nutr Biochem. 2015;26(11):1183-1192. 
8. Duncan GE, Perri MG, Theriaque DW, Hutson AD, Eckel RH, Stacpoole PW. Exercise training, without weight loss, increases insulin sensitivity and postheparin plasma lipase activity in previously sedentary adults. Diabetes Care. 2003;26(3):557-562.

9. Kesse-Guyot E, Ahluwalia N, Lassale C, Hercberg S, Fezeu L, Lairon D. Adherence to Mediterranean diet reduces the risk of metabolic syndrome: a 6-year prospective study. Nutr Metab Cardiovasc Dis. 2013; 23(7):677-683.

10. Zimmermann GR, Lehár J, Keith CT. Multi-target therapeutics: when the whole is greater than the sum of the parts. Drug Discov Today. 2007; 12(1-2):34-42.

11. Bawa P, Pradeep P, Kumar P, Choonara YE, Modi G, Pillay V. Multi-target therapeutics for neuropsychiatric and neurodegenerative disorders. Drug Discov Today. 2016;21(12):1886-1914.

12. Liu C, Xiang W, Yu Y, Shi ZQ, Huang XZ, Xu L. Comparative analysis of 1-deoxynojirimycin contribution degree to $\alpha$-glucosidase inhibitory activity and physiological distribution in Morus alba L. Ind Crop Prod. 2015;70:309-315.

13. Do HJ, Chung JH, Hwang JW, Kim OY, Lee JY, Shin MJ. 1-Deoxynojirimycin isolated from Bacillus subtilis improves hepatic lipid metabolism and mitochondrial function in high-fat-fed mice. Food Chem Toxicol. 2015;75:1-7.

14. Tsuduki T, Kikuchi I, Kimura T, Nakagawa K, Miyazawa T. Intake of mulberry 1-deoxynojirimycin prevents diet-induced obesity through increases in adiponectin in mice. Food Chem. 2013;139(1-4):16-23.

15. Chang W, Zhang M, Li J, et al. Berberine improves insulin resistance in cardiomyocytes via activation of $5^{\prime}$-adenosine monophosphateactivated protein kinase. Metabolism. 2013;62(8):1159-1167.

16. Wu U, Cha Y, Huang X, et al. Protective effects of berberine on high fat-induced kidney damage by increasing serum adiponectin and promoting insulin sensitivity. Int J Clin Exp Pathol. 2015;8(11): 14486-14492.

17. Jiang SJ, Dong H, Li JB, et al. Berberine inhibits hepatic gluconeogenesis via the LKB1-AMPK-TORC2 signaling pathway in streptozotocininduced diabetic rats. World J Gastroenterol. 2015;21(25):7777-7785.

18. Yin J, Gao Z, Liu D, Liu Z, Ye J. Berberine improves glucose metabolism through induction of glycolysis. Am J Physiol Endocrinol Metab. 2008;294(1):E148-E156.

19. Zhang X, Zhao Y, Xu J, et al. Modulation of gut microbiota by berberine and metformin during the treatment of high-fat diet-induced obesity in rats. Sci Rep. 2015;5:14405.

20. Chilelli NC, Ragazzi E, Valentini R, et al. Curcumin and boswellia serrata modulate the glyco-oxidative status and lipo-oxidation in master athletes. Nutrients. 2016;8(11)pii:E745

21. Maithilikarpagaselvi N, Sridhar MG, Swaminathan RP, Zachariah B. Curcumin prevents inflammatory response, oxidative stress and insulin resistance in high fructose fed male Wistar rats: Potential role of serine kinases. Chem-Biol Interact. 2016;244:187-194.

22. Kim HI, Kim JW, Kim SH, Cha JY, Kim KS, Ahn YH. Identification and functional characterization of the peroxisomal proliferator response element in rat GLUT2 promoter. Diabetes. 2000;49(9): $1517-1524$

23. Cha JY, Kim H, Kim KS, Hur MW, Ahn Y. Identification of transacting factors responsible for the tissue-specific expression of human glucose transporter type 2 isoform gene. Cooperative role of hepatocyte nuclear factors 1alpha and 3beta. J Biol Chem. 2000;275(24): $18358-18365$.

24. Ban N, Yamada Y, Someya Y, et al. Hepatocyte nuclear factor-1alpha recruits the transcriptional co-activator p300 on the GLUT2 gene promoter. Diabetes. 2002;51(5):1409-1418.

25. David-Silva A, Freitas HS, Okamoto MM, Sabino-Silva R, Schaan BD, Machado UF. Hepatocyte nuclear factors 1alpha/4alpha and forkhead box A2 regulate the solute carrier 2A2 (Slc2a2) gene expression in the liver and kidney of diabetic rats. Life Sci. 2013;93(22):805-813.

26. Burguera B, Dudek R, Caro J. Liver GLUT-2 protein is not upregulated in non-insulin dependent diabetes. Horm Metab Res. 1995; 27(07):341-344
27. Jung UJ, Lee M-K, Park YB, Kang MA, Choi M-S. Effect of citrus flavonoids on lipid metabolism and glucose-regulating enzyme mRNA levels in type-2 diabetic mice. Int J Biochem Cell Biol. 2006;38(7):1134-1145.

28. Slieker LJ, Sundell KL, Heath WF, et al. Glucose transporter levels in tissues of spontaneously diabetic Zucker fa/fa rat (ZDF/drt) and viable yellow mouse (Avy/a). Diabetes. 1992;41(2):187-193.

29. Matsuzaka T, Shimano H, Yahagi N, et al. Insulin-independent induction of sterol regulatory element-binding protein-1c expression in the livers of streptozotocin-treated mice. Diabetes. 2004;53(3):560-569.

30. Ahmadi S, Awliaei H, Haidarizadeh M, Rostamzadeh J. The effect of ethanolic extract of urtica dioica leaves on high levels of blood glucose and gene expression of glucose transporter 2 (Glut2) in liver of alloxaninduced diabetic mice. Gene Cell Tissue. 2015;2(3):e30355.

31. Okamoto Y, Tanaka S, Haga Y. Enhanced GLUT2 gene expression in an oleic acid-induced in vitro fatty liver model. Hepatol Res. 2002; 23(2): 138-144.

32. Farsi E, Ahmad M, Hor SY, Ahamed MBK, Yam MF, Asmawi MZ. Standardized extract of Ficus deltoidea stimulates insulin secretion and blocks hepatic glucose production by regulating the expression of glucose-metabolic genes in streptozitocin-induced diabetic rats. $B M C$ Complem Altern M. 2014;14(1):220.

33. Ma HT, Hsieh JF, Chen ST. Anti-diabetic effects of Ganoderma lucidum. Phytochemistry. 2015;114:109-113.

34. Mathur R, Dutta S, Velpandian T, Mathur S. Psidium guajava Linn. leaf extract affects hepatic glucose transporter-2 to attenuate early onset of insulin resistance consequent to high fructose intake: an experimental study. Pharmacognosy Res. 2015;7(2):166.

35. Antu KA, Riya MP, Nair A, Mishra A, Srivastava AK, Raghu KG. Symplocos cochinchinensis enhances insulin sensitivity via the down regulation of lipogenesis and insulin resistance in high energy diet rat model. J Ethnopharmacol. 2016;193:500-509.

36. Wang Q, Sun X, Li X, Dong X, Li P, Zhao L. Resveratrol attenuates intermittent hypoxia-induced insulin resistance in rats: Involvement of Sirtuin 1 and the phosphatidylinositol-4,5-bisphosphate 3-kinase/AKT pathway. Mol Med Rep. 2015;11(1):151-158.

37. Yonamine CY, Pinheiro-Machado E, Michalani ML, et al. Resveratrol improves glycemic control in insulin-treated diabetic rats: participation of the hepatic territory. Nutr Metab (Lond). 2016;13(1):44.

38. Lee B-H, Hsu W-H, Chang Y-Y, Kuo H-F, Hsu Y-W, Pan T-M. Ankaflavin: a natural novel PPAR $\gamma$ agonist upregulates Nrf2 to attenuate methylglyoxal-induced diabetes in vivo. Free Radical Bio Med. 2012; 53(11):2008-2016.

39. Lin J, Chen A. Curcumin diminishes the impacts of hyperglycemia on the activation of hepatic stellate cells by suppressing membrane translocation and gene expression of glucose transporter-2. Mol Cell Endocrino. 2011;333(2):160-171.

40. Narasimhan A, Chinnaiyan M, Karundevi B. Ferulic acid regulates hepatic GLUT2 gene expression in high fat and fructose-induced type-2 diabetic adult male rat. Eur J Pharmacol. 2015;761:391-397.

41. Celik S, Erdogan S, Tuzcu M. Caffeic acid phenethyl ester (CAPE) exhibits significant potential as an antidiabetic and liver-protective agent in streptozotocin-induced diabetic rats. Pharmacol Res. 2009; 60(4):270-276

42. Iynedjian PB, Marie S, Gjinovci A, et al. Glucokinase and cytosolic phosphoenolpyruvate carboxykinase (GTP) in the human liver. Regulation of gene expression in cultured hepatocytes. J Clin Invest. 1995;95(5): 1966-1973.

43. Brouwers MC, Jacobs C, Bast A, Stehouwer CD, Schaper NC. Modulation of glucokinase regulatory protein: a double-edged sword? Trends Mol Med. 2015;21(10):583-594.

44. Dong Q, Giorgianni F, Deng X, et al. Phosphorylation of sterol regulatory element binding protein-1a by protein kinase A (PKA) regulates transcriptional activity. Biochem Biophys Res Commun. 2014;449(4): 449-454.

45. Li Y, Xu S, Mihaylova MM, et al. AMPK phosphorylates and inhibits SREBP activity to attenuate hepatic steatosis and atherosclerosis in dietinduced insulin-resistant mice. Cell Metab. 2011;13(4):376-388. 
46. Yoon YS, Seo WY, Lee MW, Kim ST, Koo SH. Salt-inducible kinase regulates hepatic lipogenesis by controlling SREBP-1c phosphorylation. J Biol Chem. 2009;284(16):10446-10452.

47. Tian J, Goldstein JL, Brown MS. Insulin induction of SREBP-1c in rodent liver requires LXRalpha-C/EBPbeta complex. Proc Natl Acad Sci U S A. 2016;113(29):8182-8187.

48. Filhoulaud G, Guilmeau S, Dentin R, Girard J, Postic C. Novel insights into ChREBP regulation and function. Trends Endocrinol Metab. 2013;24(5):257-268.

49. Kawaguchi T, Osatomi K, Yamashita H, Kabashima T, Uyeda K. Mechanism for fatty acid "sparing" effect on glucose-induced transcription: regulation of carbohydrate-responsive element-binding protein by AMPactivated protein kinase. J Biol Chem. 2002;277(6):3829-3835.

50. Lowes W, Walker M, Alberti KG, Agius L. Hexokinase isoenzymes in normal and cirrhotic human liver: suppression of glucokinase in cirrhosis. Biochim Biophys Acta. 1998;1379(1):134-142.

51. Haeusler RA, Camastra S, Astiarraga B, Nannipieri M, Anselmino M, Ferrannini E. Decreased expression of hepatic glucokinase in type 2 diabetes. Mol Metab. 2015;4(3):222-226.

52. Matschinsky FM, Zelent B, Doliba N, et al. Glucokinase activators for diabetes therapy. Diabetes Care. 2011;34(Suppl 2):S236-S243.

53. Johnson TO, Humphries PS. Glucokinase activators for the treatment of type 2 diabetes. Ann Rep Med Chem. 2006;41:141-154.

54. Lu JM, Wang YF, Yan HL, Lin P, Gu W, Yu J. Antidiabetic effect of total saponins from Polygonatum kingianum in streptozotocin-induced diabetic rats. J Ethnopharmacol. 2016;179:291-300.

55. Sasikala C, Sudhakar Y. Antidiabetic and hypolipidemic effects of methanolic extract of Ventilago maderaspatana in streptozotocin induced diabetic rats. Asian J Pharm Clin Res. 2014;7:58-60.

56. Abirami RG, S. K. Antidiabetic activity of Ulva fasciata and its impact on carbohydrate metabolism enzymes in alloxan induced diabetic rats. Int J Res Phytochem Pharmacol. 2013;3(3):136-141.

57. Shetti AA, Sanakal RD, Kaliwal BB. Antidiabetic effect of ethanolic leaf extract of Phyllanthus amarus in alloxan induced diabetic mice. Asian J Plant Sci Res. 2012;2(1):11-15.

58. Vidhya R, Gandhi GR, Jothi G, Radhika J, Brindha P. Evaluation of antidiabetic potential of Achyranthes aspera Linn. on alloxan induced diabetic animals. Int J Pharm Pharm Sci. 2012;4(5):577-580.

59. Xing XH, Zhang ZM, Hu XZ, Wu RQ, Xu C. Antidiabetic effects of Artemisia sphaerocephala Krasch. gum, a novel food additive in China, on streptozotocin-induced type 2 diabetic rats. J Ethnopharmacol. 2009;125(3):410-416.

60. Ni G, Shen ZF, Lu Y, et al. Glucokinase-activating sesquinlignans from the rhizomes of Acorus tatarinowii Schott. J Org Chem. 2011; 76(7):2056-2061.

61. He H, Yu WG, Yang JP, Ge S, Lu YH. Multiple comparisons of glucokinase activation mechanisms of five mulberry bioactive ingredients in hepatocyte. J Arg Food Chem. 2015;64(12):2475-2484.

62. Moore MC, Coate KC, Winnick JJ, An Z, Cherrington AD. Regulation of hepatic glucose uptake and storage in vivo. Adv Nutr. 2012;3(3): 286-294.

63. Acheson KJ, Schutz Y, Bessard T, Anantharaman K, Flatt JP, Jequier E. Glycogen storage capacity and de novo lipogenesis during massive carbohydrate overfeeding in man. Am J Clin Nutr. 1988;48(2):240-247.

64. Patel S, Doble BW, MacAulay K, Sinclair EM, Drucker DJ, Woodgett JR Tissue-specific role of glycogen synthase kinase 3beta in glucose homeostasis and insulin action. Mol Cell Biol. 2008;28(20):6314-6328.

65. Alwahsh SM, Dwyer BJ, Forbes S, Thiel DH, Lewis PJ, Ramadori G. Insulin production and resistance in different models of diet-induced obesity and metabolic syndrome. Int J Mol Sci. 2017;18(2)pii:E285.

66. Garcia-Monzon C, Lo Iacono O, Mayoral R, et al. Hepatic insulin resistance is associated with increased apoptosis and fibrogenesis in nonalcoholic steatohepatitis and chronic hepatitis C. J Hepatol. 2011; 54(1):142-152.

67. Chen H, Fajol A, Hoene M, et al. PI3K-resistant GSK3 controls adiponectin formation and protects from metabolic syndrome. Proc Natl Acad Sci U S A. 2016;113(20):5754-5759.
68. Gao C, Holscher C, Liu Y, Li L. GSK3: a key target for the development of novel treatments for type 2 diabetes mellitus and Alzheimer disease. Rev Neurosci. 2011;23(1):1-11.

69. MacAulay K, Woodgett JR. Targeting glycogen synthase kinase-3 (GSK-3) in the treatment of Type 2 diabetes. Expert opin Ther Tar. 2008;12(10):1265-1274.

70. Lin CL, Lin JK. Epigallocatechin gallate (EGCG) attenuates high glucose-induced insulin signaling blockade in human hepG2 hepatoma cells. Mol Nutr Food Res. 2008;52(8):930-939.

71. Tang D, Chen QB, Xin XL, Aisa HA. Anti-diabetic effect of three new norditerpenoid alkaloids in vitro and potential mechanism via PI3K/Akt signaling pathway. Biomed Pharmacother. 2017;87:145-152.

72. Azevedo MF, Camsari Ç, Sá CM, Lima CF, Fernandes-Ferreira M, Pereira-Wilson C. Ursolic acid and luteolin-7-glucoside improve lipid profiles and increase liver glycogen content through glycogen synthase kinase-3. Phytother Res. 2010;24(Supp1 2):S220-S224.

73. Alwahsh SM, Gebhardt R. Dietary fructose as a risk factor for nonalcoholic fatty liver disease (NAFLD). Arch Toxicol. 2017;91(4): 1545-1563.

74. Bergheim I, Guo L, Davis MA, et al. Metformin prevents alcoholinduced liver injury in the mouse: Critical role of plasminogen activator inhibitor-1. Gastroenterology. 2006;130(7):2099-2112.

75. Spruss A, Kanuri G, Stahl C, Bischoff SC, Bergheim I. Metformin protects against the development of fructose-induced steatosis in mice: role of the intestinal barrier function. Lab Invest. 2012;92(7): 1020-1032.

76. Burchell A, Cain DI. Rat hepatic microsomal glucose-6-phosphatase protein levels are increased in streptozotocin-induced diabetes. Diabetologia. 1985;28(11):852-856.

77. Argaud D, Zhang Q, Pan W, Maitra S, Pilkis SJ, Lange AJ. Regulation of rat liver glucose-6-phosphatase gene expression in different nutritional and hormonal states: gene structure and $5^{\prime}$-flanking sequence. Diabetes. 1996;45(11):1563-1571.

78. Li Y, Mechin MC, van de Werve G. Diabetes affects similarly the catalytic subunit and putative glucose-6-phosphate translocase of glucose-6-phosphatase. J Biol Chem. 1999;274(48):33866-33868.

79. Oikonomakos NG, Tiraidis C, Leonidas DD, et al. Iminosugars as potential inhibitors of glycogenolysis: structural insights into the molecular basis of glycogen phosphorylase inhibition. J Med Chem. 2006; 49(19):5687-5701.

80. Andersen B, Rassov A, Westergaard N, Lundgren K. Inhibition of glycogenolysis in primary rat hepatocytes by 1, 4-dideoxy-1,4-iminoD-arabinitol. Biochem J. 1999;342(Pt 3):545-550.

81. Tsitsanou KE, Hayes JM, Keramioti M, et al. Sourcing the affinity of flavonoids for the glycogen phosphorylase inhibitor site via crystallography, kinetics and QM/MM-PBSA binding studies: comparison of chrysin and flavopiridol. Food Chem Toxicol. 2013;61:14-27.

82. Kantsadi AL, Apostolou A, Theofanous S, et al. Biochemical and biological assessment of the inhibitory potency of extracts from vinification byproducts of Vitis vinifera extracts against glycogen phosphorylase. Food Chem Toxicol. 2014;67:35-43.

83. Kamiyama O, Sanae F, Ikeda K, et al. In vitro inhibition of $\alpha$-glucosidases and glycogen phosphorylase by catechin gallates in green tea. Food Chem. 2010;122(4):1061-1066.

84. Liang Z, Zhang L, Li L, et al. Identification of pentacyclic triterpenes derivatives as potent inhibitors against glycogen phosphorylase based on 3D-QSAR studies. Eur J Med Chem. 2011;46(6):2011-2021.

85. Meng S, Cao J, Feng Q, Peng J, Hu Y. Roles of chlorogenic acid on regulating glucose and lipids metabolism: a review. Evid Based Complement Alternat Med. 2013;2013:801457.

86. De Abreu MB, Temraz A, Malafronte N, Gonzalez-Mujica F, Duque S, Braca A. Phenolic derivatives from Ruprechtia polystachya and their inhibitory activities on the glucose-6-phosphatase system. Chem Biodivers. 2011;8(11):2126-2134.

87. Estrada O, Hasegawa M, Gonzalez-Mujica F, et al. Evaluation of flavonoids from Bauhinia megalandra leaves as inhibitors of glucose6-phosphatase system. Phytother Res. 2005;19(10):859-863. 
88. Lee TS, Das A, Khosla C. Structure-activity relationships of semisynthetic mumbaistatin analogs. Bioorgan Med Chem. 2007;15(15): 5207-5218.

89. Liu HY, Fang M, Zhang YQ. In vivo hypoglycaemic effect and inhibitory mechanism of the branch bark extract of the mulberry on STZinduced diabetic mice. ScientificWorldJournal. 2014;2014:614265.

90. Shih CC, Chen MH, Lin CH. Validation of the Antidiabetic and Hypolipidemic Effects of Clitocybe nuda by Assessment of Glucose Transporter 4 and Gluconeogenesis and AMPK Phosphorylation in Streptozotocin-Induced Mice. Evid Based Complement Alternat Med. 2014;2014:705636.

91. Zhou JY, Zhou SW, Zhang KB, et al. Chronic effects of berberine on blood, liver glucolipid metabolism and liver PPARs expression in diabetic hyperlipidemic rats. Biol Pharm Bull. 2008;31(6):1169-1176.

92. Zhou L, Yang Y, Wang X, et al. Berberine stimulates glucose transport through a mechanism distinct from insulin. Metabolism. 2007; 56(3):405-412.

93. Kong WJ, Zhang H, Song DQ, et al. Berberine reduces insulin resistance through protein kinase $\mathrm{C}$-dependent up-regulation of insulin receptor expression. Metabolism. 2009;58(1):109-119.

94. Yu Y, Liu L, Wang X, et al. Modulation of glucagon-like peptide-1 release by berberine: in vivo and in vitro studies. Biochem Pharmacol. 2010;79(7):1000-1006.

95. Li YQ, Zhou FC, Gao F, Bian JS, Shan F. Comparative evaluation of quercetin, isoquercetin and rutin as inhibitors of $\alpha$-glucosidase. J Arg Food Chem. 2009;57(24):11463-11468.

96. Kwon O, Eck P, Chen $\mathrm{S}$, et al. Inhibition of the intestinal glucose transporter GLUT2 by flavonoids. FASEB J. 2007;21(2):366-377.

97. Gasparin FRS, Spitzner FL, Ishii-Iwamoto EL, Bracht A, Constantin J. Actions of quercetin on gluconeogenesis and glycolysis in rat liver. Xenobiotica. 2003;33(9):903-911.

98. Pisonero-Vaquero S, Martínez-Ferreras Á, García-Mediavilla MV, et al. Quercetin ameliorates dysregulation of lipid metabolism genes via the PI3K/AKT pathway in a diet-induced mouse model of nonalcoholic fatty liver disease. Mol Nutr Food Res. 2015;59(5):879-893.

99. Eid HM, Nachar A, Thong F, Sweeney G, Haddad PS. The molecular basis of the antidiabetic action of quercetin in cultured skeletal muscle cells and hepatocytes. Pharmacogn Mag. 2015;11(41):74-81.

100. Dong J, Zhang X, Zhang L, et al. Quercetin reduces obesity-associated ATM infiltration and inflammation in mice: a mechanism including AMPK $\alpha 1 /$ SIRT1. J Lipid Res. 2014;55(3):363-374.

101. Fang XK, Gao J, Zhu DN. Kaempferol and quercetin isolated from Euonymus alatus improve glucose uptake of 3T3-L1 cells without adipogenesis activity. Life Sci. 2008;82(11):615-622.

102. Chuang CC, Martinez K, Xie G, et al. Quercetin is equally or more effective than resveratrol in attenuating tumor necrosis factor$\alpha$-mediated inflammation and insulin resistance in primary human adipocytes. Am J Clin Nutr. 2010;92(6):1511-1521.

103. Youl E, Bardy G, Magous R, et al. Quercetin potentiates insulin secretion and protects INS-1 pancreatic $\beta$-cells against oxidative damage via the ERK1/2 pathway. Brit J Pharmacol. 2010;161(4):799-814.

104. Yonamine CY, Pinheiro-Machado E, Michalani ML, et al. Resveratrol improves glycemic control in insulin-treated diabetic rats: participation of the hepatic territory. Nutr Metab (Lond). 2016;13:44.

105. Park JM, Kim TH, Bae JS, Kim MY, Kim KS, Ahn YH. Role of resveratrol in FOXO1-mediated gluconeogenic gene expression in the liver. Biochem Biophys Res Commun. 2010;403(3-4):329-334.

106. Ganjam GK, Dimova EY, Unterman TG, Kietzmann T. FoxO1 and HNF-4 are involved in regulation of hepatic glucokinase gene expression by resveratrol. J Biol Chem. 2009;284(45):30783-30797.

107. Breen DM, Sanli T, Giacca A, Tsiani E. Stimulation of muscle cell glucose uptake by resveratrol through sirtuins and AMPK. Biochem Biophys Res Commun. 2008;374(1):117-122.

108. Vetterli L, Maechler P. Resveratrol-activated SIRT1 in liver and pancreatic beta-cells: a Janus head looking to the same direction of metabolic homeostasis. Aging (Albany NY). 2011;3(4):444-449.
109. Deng JY, Hsieh PS, Huang JP, Lu LS, Hung LM. Activation of estrogen receptor is crucial for resveratrol-stimulating muscular glucose uptake via both insulin-dependent and -independent pathways. Diabetes. 2008;57(7):1814-1823.

110. Wang S, Liang X, Yang Q, et al. Resveratrol induces brown-like adipocyte formation in white fat through activation of AMP-activated protein kinase (AMPK) alpha1. Int J Obes (Lond). 2015;39(6):967-976.

111. Yasui K, Tanabe H, Miyoshi N, et al. Effects of (-)-epigallocatechin3-O-gallate on expression of gluconeogenesis-related genes in the mouse duodenum. Biomed Res. 2011;32(5):313-320.

112. Lin CL, Lin JK. Epigallocatechin gallate (EGCG) attenuates high glucose-induced insulin signaling blockade in human hepG2 hepatoma cells. Mol Nutr Food Res. 2008;52(8):930-939.

113. Waltner-Law ME, Wang XL, Law BK, Hall RK, Nawano M, Granner DK. Epigallocatechin gallate, a constituent of green tea, represses hepatic glucose production. J Biol Chem. 2002;277(38):34933-34940.

114. Zhang ZF, Li Q, Liang J, et al. Epigallocatechin-3-O-gallate (EGCG) protects the insulin sensitivity in rat L6 muscle cells exposed to dexamethasone condition. Phytomedicine. 2010;17(1):14-18.

115. Li Y, Zhao S, Zhang W, et al. Epigallocatechin-3-O-gallate (EGCG) attenuates FFAs-induced peripheral insulin resistance through AMPK pathway and insulin signaling pathway in vivo. Diabetes Res Clin Pr. 2011;93(2):205-214.

116. Pournourmohammadi S, Grimaldi M, Stridh MH, et al. Epigallocatechin-3-gallate (EGCG) activates AMPK through the inhibition of glutamate dehydrogenase in muscle and pancreatic $\beta$-cells: a potential beneficial effect in the pre-diabetic state? Int J Biochem Cell Biol. 2017;88:220-225.

117. Centeno-Baez C, Dallaire P, Marette A. Resveratrol inhibition of inducible nitric oxide synthase in skeletal muscle involves AMPK but not SIRT1. Am J Physiol Endocrinol Metab. 2011;301(5):E922-E930.

118. Song EK, Hur H, Han MK. Epigallocatechin gallate prevents autoimmune diabetes induced by multiple low doses of streptozotocin in mice. Arch Pharm Res. 2003;26(7):559-563.

119. Najafian M. The effects of curcumin on alpha amylase in diabetics rats. Zahedan J Res Med Sci. 2015;17(12):e5198.

120. Bustanji Y, Taha MO, Almasri IM, Al-Ghussein MAS, Mohammad MK, Alkhatib HS. Inhibition of glycogen synthase kinase by curcumin: Investigation by simulated molecular docking and subsequent in vitro/ in vivo evaluation. J Enzym Inhib Med Ch. 2009;24(3):771-778.

121. Kim T, Davis J, Zhang AJ, He X, Mathews ST. Curcumin activates AMPK and suppresses gluconeogenic gene expression in hepatoma cells. Biochem Biophys Res Commun. 2009;388(2):377-382.

122. Ejaz A, Wu D, Kwan P, Meydani M. Curcumin inhibits adipogenesis in 3T3-L1 adipocytes and angiogenesis and obesity in C57/BL mice. J Nutr. 2009;139(5):919-925.

123. Jimenez-Flores LM, Lopez-Briones S, Macias-Cervantes MH, Ramirez-Emiliano J, Perez-Vazquez V. A PPARgamma, NF-kappaB and AMPK-dependent mechanism may be involved in the beneficial effects of curcumin in the diabetic $\mathrm{db} / \mathrm{db}$ mice liver. Molecules. 2014; 19(6):8289-8302.

124. Kim JH, Park JM, Kim EK, et al. Curcumin stimulates glucose uptake through AMPK-p38 MAPK pathways in L6 myotube cells. J Cell Physiol. 2010;223(3):771-778.

125. Kang C, Kim E. Synergistic effect of curcumin and insulin on muscle cell glucose metabolism. Food Chem Toxicol. 2010;48(8-9): 2366-2373.

126. Xia X, Yan J, Shen Y, et al. Berberine improves glucose metabolism in diabetic rats by inhibition of hepatic gluconeogenesis. PLoS One. 2011;6(2):e16556.

127. Zhou J, Zhou S, Tang J, et al. Protective effect of berberine on beta cells in streptozotocin- and high-carbohydrate/high-fat diet-induced diabetic rats. Eur J Pharmacol. 2009;606(1-3):262-268.

128. DeFronzo RA, Simonson DC. Oral sulfonylurea agents suppress hepatic glucose production in non-insulin-dependent diabetic individuals. Diabetes Care. 1984;7(Suppl 1):72-80. 
129. Tsumura Y, Tsushima Y, Tamura A, et al. TMG-123, a novel glucokinase activator, exerts durable effects on hyperglycemia without increasing triglyceride in diabetic animal models. PLoS One. 2017;12(2):e0172252.

130. Min Q, Cai X, Sun W, et al. Identification of mangiferin as a potential Glucokinase activator by structure-based virtual ligand screening. Sci Rep. 2017;7:44681.

131. Imran M, Arshad MS, Butt MS, Kwon JH, Arshad MU, Sultan MT. Mangiferin: a natural miracle bioactive compound against lifestyle related disorders. Lipids Health Dis. 2017;16(1):84.

132. Duhault J, Lavielle R. History and evolution of the concept of oral therapy in diabetes. Diabetes Res Clin Pract. 1991;14(Suppl 2):S9-S13.

133. Isoda K, Young JL, Zirlik A, et al. Metformin inhibits proinflammatory responses and nuclear factor-kappaB in human vascular wall cells. Arterioscl Throm Vas. 2006;26(3):611-617.

134. Caliceti C, Franco P, Spinozzi S, Roda A, Cicero AF. Berberine: new insights from pharmacological aspects to clinical evidences in the management of metabolic disorders. Curr Med Chem. 2016;23(14): 1460-1476.

135. Lee YS, Kim WS, Kim KH, et al. Berberine, a natural plant product, activates AMP-activated protein kinase with beneficial metabolic effects in diabetic and insulin-resistant states. Diabetes. 2006;55(8): 2256-2264.

136. Marcovecchio ML, Chiarelli F. Pharmacotherapy options for pediatric diabetes. Curr Opin Pediatr. 2017;29(4):481-487.
137. Yin J, Zhang H, Ye J. Traditional chinese medicine in treatment of metabolic syndrome. Endocr Metab Immune Disord Drug Targets. 2008;8(2):99-111.

138. Azushima K, Tamura K, Wakui H, et al. Bofu-tsu-shosan, an oriental herbal medicine, exerts a combinatorial favorable metabolic modulation including antihypertensive effect on a mouse model of human metabolic disorders with visceral obesity. PLoS One. 2013; 8(10):e75560.

139. Gao J, Li J, An Y, et al. Increasing effect of Tangzhiqing formula on IRS-1-dependent PI3K/AKT signaling in muscle. BMC Complement Altern Med. 2014;14(1):198.

140. Qian Q, Liu X, He W, et al. TG accumulation inhibitory effects of Jinqi formula by AMPK signaling pathway. J Ethnopharmacol. 2012; 143(1):41-48.

141. Schadt EE, Bjorkegren JL. NEW: network-enabled wisdom in biology, medicine, and health care. Sci Transl Med. 2012;4(115):115rv1.

142. Gu J, Gui Y, Chen L, Yuan G, Lu HZ, Xu X. Use of natural products as chemical library for drug discovery and network pharmacology. PLoS One. 2013;8(4):e62839.

143. Zhang L, Song C, Miao G, et al. Novel Liver-targeted conjugates of Glycogen Phosphorylase Inhibitor PSN-357 for the Treatment of Diabetes: Design, Synthesis, Pharmacokinetic and Pharmacological Evaluations. Sci Rep. 2017;7:42251.
Drug Design, Development and Therapy

\section{Publish your work in this journal}

Drug Design, Development and Therapy is an international, peerreviewed open-access journal that spans the spectrum of drug design and development through to clinical applications. Clinical outcomes, patient safety, and programs for the development and effective, safe, and sustained use of medicines are the features of the journal, which

\section{Dovepress}

has also been accepted for indexing on PubMed Central. The manuscript management system is completely online and includes a very quick and fair peer-review system, which is all easy to use. Visit http://www.dovepress.com/testimonials.php to read real quotes from published authors.

Submit your manuscript here: http://www.dovepress.com/drug-design-development-and-therapy-journal 